\title{
Craniofacial and cutaneous findings in Noonan, Costello and LEOPARD syndromes
}

\author{
Rafał Pokrowiecki', Piotr Chomik ${ }^{1}$, Maciej Borowiec ${ }^{1}$, Krzysztof Dowgierd ${ }^{1}$, Anna Starzyńska² \\ 'Department of Maxillofacial Surgery, Voivodeship Specialist Children's Hospital, Olsztyn, Poland \\ 2Department of Oral Surgery, Medical University of Gdansk, Gdansk, Poland
}

Adv Dermatol Allergol 2018; XXXV (5): 437-441

DOI: https://doi.org/10.5114/pdia.2017.70330

\begin{abstract}
Noonan, Costello and LEOPARD syndromes belong to a family of cardiofaciocutaneous disorders and share common genetic traits. As they are associated with a germline mutation in genes encoding proteins involved in RAS/MAPK, patients suffering from these syndromes are at a greater risk of cancer and abnormal myelopoiesis in infancy. Patients with cardio faciocutaneous syndromes share some clinically overlapping syndromes, therefore differential diagnosis can be problematic. In this paper we aim at demonstrating distinctive craniofacial and cutaneous manifestations of Noonan, Costello and LEOPARD syndromes which can be useful for clinicians who aim at treatment of children with rare diseases.
\end{abstract}

Key words: Noonan, Costello, LEOPARD, craniofacial, cutaneous.

\section{Introduction}

Craniofacial and dental characteristics that are seen since birth and the skin condition which are involved in more than $1 / 3$ of reported syndromes may be diagnostic clues indicating the presence of other pathologies [1]. The neuro-cardio-facial-cutaneous (NCFC) syndromes belong to a group of hereditary diseases that present a number of phenotypic features of a varying degree. Cranial dysmorphia and cutaneous anomalies are accompanied by delayed growth, cardiac malformations, blood diseases and mental retardation [2]. Noonan, Costello, Leopard, Cardio-Facio-Cutaneous and Neurofibromatosis - type 1 belong to the NCFC syndromes and share a common genetic and pathophysiologic basis [3]. Disease development is associated with a germline mutation in genes encoding proteins involved in the RAS/MAPK (rat sarcoma/ mitogen-activated protein kinase) signaling pathway. Therefore, NCFC syndromes belong to the RASopathies [4], which predispose to cancer and abnormal myelopoiesis in infancy [5]. As these syndromes share clinically overlapping symptoms, differential diagnosis is frequently problematic. In this comprehensive review we aim at elucidating characteristics of different NCFC syndromes which might be helpful in daily clinical practice.

\section{Noonan syndrome}

Noonan syndrome (NS) is the most common syndrome among NCFC disorders. The incidence is $1 \mathrm{in}$ 1000 and 1 in 2500 live births [6] and is panethnic. Other names of this syndrome are female pseudo-Turner syndrome; male Turner syndrome, Turner phenotype with normal chromosomes. Noonan syndrome is an autosomal dominant developmental disorder that causes congenital heart defects, myeloproliferative disorders, chest deformity (sunken chest or a protruding chest), cryptorchidism in males, short stature and webbed neck $[7,8]$. There are 5 genotypes that imply a clinical phenotype of the patients with NS: PTPN11 (over 50\%), SOS1 (10\%), RAF1 (10\%), KRAS (2\%) and NRAS (<1\%) [9]. Birthweight and body length are usually normal but infants have feeding difficulties that can lead to failure to thrive [9]. Newborns represent distinctive facial dysmorphia and a large head compared to the face with tall forehead with narrow templates [10]. Recent studies indicate that in some cases, NS may be accompanied by craniosynostosis, of which a sagittal variant is most commonly reported [11]. Presence of craniosynostosis may mask the child's NSs phenotype and impede proper diagnosis [11]. Eyes are wide-spaced (hypertelorism) with epicanthal folds and downward slant of palpebral fissures,

Address for correspondence: Piotr Chomik DMD, Department of Maxillofacial Surgery, Voivodeship Specialist Children's Hospital, 7 Dębinki St, 80-952 Olsztyn, Poland, phone: +48 505172 685, fax: +48 58349 21 33, e-mail: piotr.chomik@gumed.edu.pl Received: 6.04.2018, accepted: 21.06.2018. 


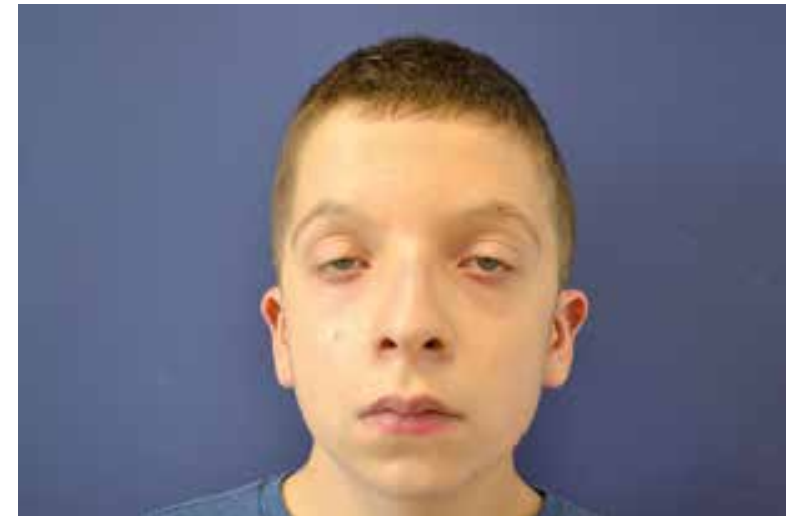

Figure 1. Emotionless face of the patient with Noonan syndrome

which result in characteristic thick hooded eyelids. Strabismus, amblyopia or refractive errors may also be seen [12]. Occasionally patients may also have coloboma [13]. The nose is short, wide, with a depressed root and full tip [14]. Midface hypoplasia is caused by micrognathia, which results in a high arched palate [15]. Lips are usually thick [16]. Intraorally, macroglossia with glossoptosis and narrowed choanae may be diagnosed [17]. This may cause a poor sucking function, prolonged feeding time, recurrent vomiting and obstructive sleep apnea. Low-set posteriorly rotated ears, with a thick helix (pinnae) is characteristic of newborns with NS [5].

Cutaneous findings include a distinctive short neck with excess nuchal skin and a low posterior hairline [14]. Frequently diagnosed generalized lymphedema results in swollen edematous, "sausage like" fingers and toes. Infants have wispy hair. Some craniofacial features change with the patient's age [18]. Facial shapes in early childhood become more coarse, triangular, with a wide forehead and narrow and pointed chin. A child's face may look emotionless (Figure 1). The neck is longer and represents accentuated webbing-pterygium colli $[15,18]$. Adults are characterized by a triangle shaped head with a high anterior hairline, arched and diamond-shaped eyebrows, transparent and wrinkled skin, prominent nasolabial folds and less prominent eyes than adolescents $[9,14,19]$. Micrognathia, malocclusion, crowding of the teeth (Figure 2), articulation difficulties and speech disorders are common problems. Excessive gingival exposure at smile, open bite and increased overjet, oligodontia and dental deformities are frequent [20]. Recurrent ulcers of oral mucosa are seen in $22 \%$ of patients [21]. Pathognomonic features that do not change with age are low-set posteriorly rotated ears, highly arched eyebrows and blue or green iris that is usually lighter than in that of parents. Due to congenital heart disease, hypoxia may cause bluish discoloration of the skin and mucous membranes.

Noonan syndrome is associated with increased ERKactivity induced by RAS activation and, therefore, RANKL

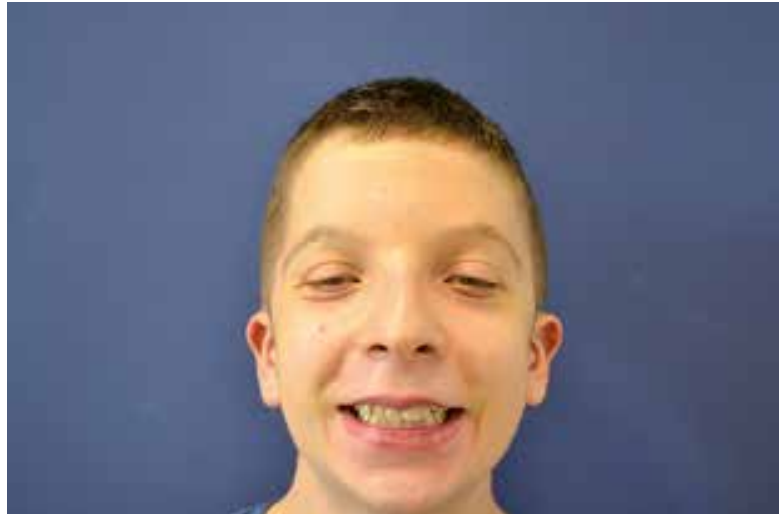

Figure 2. Crowding of teeth and malocclusion in the patient with Noonan syndrome

up-regulation may lead to development of multiple central giant cell lesions (CGCLs) of the jaws and other parts of the body $[22,23]$. Co-occurrence of the NS phenotype with multiple CGCLs was named Noonan-like/multiple giant cell lesion syndrome (Noonan-like/MGCL) [22, 23]. However, it is still unclear whether Noonan-like/MGCL should be regarded as a separate entity or as a part of the NS spectrum [22].

From early childhood, such skin manifestations may be observed as dry skin, dystrophic nails, extra prominence on pads of fingers and toes, follicular keratosis, hyperelastic skin, moles, multiple lentigines, nevi, caféau-lait spots, sometimes vitiligo, thick curly hair or thin sparse hair [6, 19, 24]. More naevi, lentigines and caféau-lait spots are attributed to the RAF1 genotype [9]. Moreover, multiple lentigines may be accompanied by aforementioned MCGCL lesions [24]. Vitiligo should be considered as a potential sign of other autoimmune diseases and requires diagnosis of thyroid hormones and a blood level of glucose. Skin lesions should be examined by a dermatologist. Vitiligo or café-au-lait spots may require observation only. However, higher susceptibility of patients with NS to infections may require antibiotic therapy in acute furunculosis. In case of keratosis pilaris and/or ulerythema emollients, keratolytic agents or short courses of topical steroids are advised. Retinoids should not be regarded the first treatment choice because of limited efficiency in NS patients. Long hot baths, perfumed soaps and dry atmosphere should be limited in order to reduce skin dryness. Also, a tendency to form extensive keloids following surgical procedures was described in these patients [13].

A flattened forehead or sagittal craniosynostosis may require neurosurgical and maxillofacial procedures such as cranial vault reconstruction, cranioplasty or monoblock osteotomies with horizontal advancement. Maxillary atresia, posterior crossbite and anterior open bite, mandibular micrognathia with a clockwise rotation and malocclusion are common in patients with NS $[25,26]$. 
Therefore, these patients may require long-term orthodontic treatment followed by orthognathic surgery [27]. The MCGCL lesions require a gross total bone resection, which results in post-ablative deformities. These can be repaired with microvascularized tissue flaps and oral implant-supported prosthesis. An orthopantomogram should be recommended in patients with progressive facial coarsening [7].

\section{LEOPARD syndrome (Noonan syndrome subtype with multiple lentigines)}

LEOPARD syndrome is an autosomal dominant disorder resembling Noonan syndrome, but with additional unique phenotypic features [9]. LEOPARD syndrome (LS) acronym stands for multiple lentigines (L), ECG abnormalities (E), ocular hypertelorism $(\mathrm{O})$, pulmonary stenosis $(P)$, abnormalities of genitalia $(A)$, retardation of growth (R) and deafness (D). Craniofacial features in early years include ocular hypertelorism (100\% of cases), palpebral fissures, ptosis, "hooded" eyelids, prominent upper lip and low-set, prominent external ears. In later years, mandibular prognathism may be observed. These craniofacial characteristics, however, are less pronounced than in NS. Intraorally, relative macroglossia, highly arched palate and dental abnormalities, including multiple caries lesions and tooth agenesis are reported [28, 29]. Dental anomalies in LS are most probably due to retardation or lack of migration of the neural crest cells. Therefore, it was proposed to add dental and craniofacial anomalies to the "D" of LEOPARD acronym [29]. Distinctive cutaneous findings in LS are multiple lentigines which can be observed since the fifth year of life and increase into the thousands by puberty [30]. Some individuals with NSML do not exhibit lentigines. Lentiginosis is the most common feature and usually is the first clinical manifestation of LS. They are brown to black in color, usually $1 \mathrm{~mm}$ to $2 \mathrm{~mm}$ in size, located on the face, neck, upper trunk, with some involvement of the extremities but oral mucosa is sparsely involved [31-33]. When present on oral mucosa, differential diagnosis of Carney complex should be performed. Spots larger than $2 \mathrm{~mm}$ are clinically called café noir spots, and can exceed even $5 \mathrm{~cm}$. As these represent different histologic patterns than lentigines, a skin biopsy is necessary to distinguish them from melanocytic nevi [32]. LEOPARD syndrome shares features similar to Noonan syndrome, including facial dysmorphism, cardiac defects and autosomal inheritance [13]. Recently, LS has been regarded as a NS subtype with multiple lentigines $[34,35]$.

\section{Costello syndrome}

Costello syndrome (CS) is a very rare autosomal dominant genetic condition caused by mutations in the HRAS gene [36]. Patients with CS are characterized by intellectual disability, growth retardation, distinctive face, loose skin, cardiomyopathy and a predisposition to malignancies [37]. Features typical of newborns with CS include overgrowth at birth with a subsequent severe failure to thrive and feeding problems [38]. Major maxillofacial symptoms in neonates are relative macrocephaly (over 50\% of the newborns) [39] with a prominent, sometimes deeply creased, and hirsute forehead [40, 41]. Persistent or late anterior fontanelle, prominent scalp veins and capillary hemangioma over the glabella were also reported [40]. Newborns represent more temporal narrowing than NS and CFCS [42].

Cheeks are full and the nose is usually short with a broad nasal tip and anteverted nostrils which gives it a bulbous shape. Lips are thick and ears are posteriorly rotated with marked earlobes [43]. Eyes are deeply seated with epicanthal folds, strabismus and downward slanted palpebral fissures. The face is in general of coarse impression [40]. Maxillofacial features are remarkably consistent regardless of sex or ethnic background [44].

Redundant and wrinkled skin folds across the limbs and neck are pathognomonic for newborns with CS [39, 45]. Also, ulnar deviation at wrist with splaying of fingers, deeply grooved palms and plantar furrows are very characteristic $[45,46]$. The skin is soft, of velvety texture in over $60 \%$ of cases of CS. Fair, mild or dark hyperpigmentation of the skin is reported in almost $100 \%$ of individuals with CS. $72 \%$ to $100 \%$ of patients with cutaneous wart-like papillomas is reported [47]. Papillomata may be absent in infancy but may appear in childhood (usually since the second year of life) [44].

The most common location of the papillomas is the alar rim of the nose $[47,48]$. These usually become more apparent with age and recur after surgical removal. Most commonly reported locations of papillomas are eyelids, ears, the neck, arms, fingers and perianal region. Multiple papillomas are pathognomonic for CS as these do not occur in other CFCs. Keratosis pilaris is significantly less common in CS than in CFCs. However, palmoplantar keratoderma, acanthosis nigricans and nail abnormalities (thin, pliable, upturned) with fast growth are very common [39, 47]. Also, calcified epitheliomas, dermoid cysts, mammary fibroadenosis, and syringomas have been reported [49]. Acanthosis nigricans lesions are treated due to cosmetic reasons. These usually respond good to the topical use of keratolytics and triple-combination of depigmenting cream [50].

Eyebrows are thick and full, contrarily to other CFCs. Hair is curly and sparse at temples, grows slowly and exhibits tendency to frontal balding [47, 48]. Patients frequently suffer from increased heat intolerance, itchy skin, sweating and characteristic odor. Multiple nevi are infrequent in CS [47].

Patients with CS suffer from macroglossia and large mouth which previously was regarded as macrostomia that significantly differed CS from NS [13, 39]. Recent an- 
thropometric studies in CS revealed that mouth width did not exceed the normal range. Impression of a wide mouth is caused by lower face hypoplasia, distinctive appearance of the nose and lips [42]. Therefore, the term "pseudomacrostomia" should be used in CS patients. Also, when compared to other CFCS, infants with CS have the most prominent maxillary and mandibular hypoplasia [42]. Thick lips and facial hypoplasia with a pointed chin cause a convex facial profile with a tendency towards premature aging [45]. Malocclusion is caused by a highly arched palate, anterior open bite and posterior crossbite [37, 39]. Other intraoral findings are enamel hypoplasia [51], dental erosion and caries caused by aphagia and vomiting, and teeth attrition due to habits such as teeth clenching [37]. There are also cases of gingival fibromatosis, sometimes delayed eruption of primary teeth [36] and hypersecretion of salivary glands [39]. Recently, mandibular anomalies such as a thick and flat mandibular condyle process, short condylar neck, narrow mandibular notch and antegonial notching have been described as CS craniofacial features [37]. Mandibular hypoplasia, along with a loosely constructed elastic fibers tongue, pharynx, larynx, and upper esophagus [52] is responsible for poor sucking with severe swallowing difficulties, which are observed since birth [53], recurrent tracheostomy and a high prevalence of obstructive sleep-related respiratory disorders [54]. Aforementioned problems are common in other syndromes with mandibular dysplasia such as Treacher Collins, Nager and Pierre-Robin sequence. Patients with CS also have abnormal speech (hoarse voice) related to an oral motor apraxia [55]. Craniofacial care should be provided from early infancy [37]. In case of respiratory disorders and severe mandibular hypoplasia, distraction osteogenesis should be considered to improve the airway and allow tracheostomy decannulation. The first dental examination should be performed between the first and second year of life and then followed by yearly dental assessment [9]. The CS patients are at an increased risk of malignancies such as rhabdomyosarcoma, neuroblastoma and transitional carcinoma of the bladder [47]. The incidence of malignancies is approximately $15 \%$ over the lifetime [44]. Therefore, oncological screening should be meticulously performed in those patients.

\section{Conflict of interest}

The authors declare no conflict of interest.

\section{References}

1. Smithson SF, Winter RM. Diagnosis in dysmorphology: clues from the skin. Br J Dermatol 2004; 151: 953-60.

2. Bessis D. Neuro-cardio-facial-cutaneous syndrome. Ann Dermatol Vénéréol 2011; 138: 483-93.

3. Denayer E, Legius E. What's new in the neuro-cardio-facialcutaneous syndromes? Eur J Pediatr 2007; 166: 1091-8.
4. Cizmarova M, Kostalova L, Pribilincova Z, et al. Rasopathies - dysmorphic syndromes with short stature and risk of malignancy. Endocr Regul 2013; 47: 217-22.

5. Niemeyer CM. RAS diseases in children. Haematologica 2014; 99: 1653-62.

6. Agarwal P, Philip R, Gutch M, et al. The other side of Turner's: Noonan's syndrome. Indian J Endocrinol Metab 2013; 17: 794-8.

7. Neumann TE, Allanson J, Kavamura I, et al. Multiple giant cell lesions in patients with Noonan syndrome and cardio-faciocutaneous syndrome. Eur J Hum Genet 2009; 17: 420-5.

8. Jongmans MCJ, van der Burgt I, Hoogerbrugge PM, et al. Cancer risk in patients with Noonan syndrome carrying a PTPN11 mutation. Eur J Hum Genet 2011; 19: 870-4.

9. Roberts AE, Allanson JE, Tartaglia M, et al. Noonan syndrome. Lancet 2013; 381: 333-42.

10. Allanson JE. Noonan syndrome. J Med Genet 1987; 24: 9-13.

11. Addissie YA, Kotecha U, Hart RA, et al. Craniosynostosis and Noonan syndrome with KRAS mutations: expanding the phenotype with a case report and review of the literature. Am J Med Genet A 2015; 167: 2657-63.

12. Lee NB, Kelly L, Sharland M. Ocular manifestations of Noonan syndrome. Eye 1992; 6: 328-34.

13. Noonan JA. Noonan syndrome and related disorders. Prog Pediatr Cardiol 2005; 20: 177-85.

14. Allanson JE, Bohring A, Dörr HG, et al. The face of Noonan syndrome: does phenotype predict genotype. Am J Med Genet A 2010; 152A: 1960-6.

15. Romano AA, Allanson JE, Dahlgren J, et al. Noonan syndrome: clinical features, diagnosis, and management guidelines. Pediatrics 2010; 126: 746-59.

16. Digilio M, Marino B. Clinical manifestations of Noonan syndrome. Images Paediatr Cardiol 2001; 3: 19-30.

17. Khirani S, Leboulanger N, Ramirez A, et al. Life-threatening obstructive sleep apnea caused by adenoid hypertrophy in an infant with Noonan syndrome. Case Rep Pediatr 2012; 2012: 514514.

18. Allanson JE, Hall JG, Hughes HE, et al. Noonan syndrome: the changing phenotype. Am J Med Genet 1985; 21: 507-14.

19. Bhambhani V, Muenke M. Noonan syndrome. Am Fam Physician 2014; 89: 37-43.

20. Cardiel Ríos SA. Correction of a severe class II malocclusion in a patient with Noonan syndrome. Am J Orthod Dentofacial Orthop 2016; 150: 511-20.

21. Quaio C, Almeida T, Brasil A, et al. Tegumentary manifestations of Noonan and Noonan-related syndromes. Clinics 2013; 68: 1079-83.

22. Wolvius EB, de Lange J, Smeets EEJ, et al. Noonan-like/multiple giant cell lesion syndrome: report of a case and review of the literature. J Oral Maxillofac Surg 2006; 64: 1289-92.

23. Bufalino A, Carrera M, Carlos R, et al. Giant cell lesions in noonan syndrome: case report and review of the literature. Head Neck Pathol 2010; 4: 174-7.

24. van den Berg H, Schreuder WH, Jongmans $M$, et al. Multiple giant cell lesions in a patient with Noonan syndrome with multiple lentigines. Eur J Med Genet 2016; 59: 425-8.

25. Ueno T, Miyamoto JJ, Kataoka K, et al. An investigation of maxillofacial morphology and oral characteristic in patients with Noonan syndrome. Orthod Waves 2016; 75: 24-5.

26. Farias Lemos C, Duarte Caldas L, Ferreira Brasileiro B, et al. Dentofacial changes of Noonan syndrome: report of two clinical cases. Oral Surg Oral Med Oral Pathol Oral Radiol 2014; 117: e152. 
27. Sugar AW, Ezsias A, Bloom AL, et al. Orthognathic surgery in a patient with Noonan's syndrome. J Oral Maxillofac Surg 1994; 52: 421-5.

28. Urs P, Konde S, Chouta N, et al. LEOPARD syndrome: you could be the first one to diagnose! I Indian Soc Pedod Prev Dent 2015; 33: 57-60.

29. Yam AA, Faye M, Kane A, et al. Oro-dental and craniofacial anomalies in LEOPARD syndrome. Oral Dis 2001; 7: 200-2.

30. Coppin BD, Temple IK. Multiple lentigines syndrome (LEOPARD syndrome or progressive cardiomyopathic lentiginosis). J Med Genet 1997; 34: 582-6.

31. Chong WS, Klanwarin W, Giam YC. Generalized lentiginosis in two children lacking systemic associations: case report and review of the literature. Pediatr Dermatol 2004; 21: 139-45.

32. Bujaldón AR. LEOPARD syndrome: what are café noir spots? Pediatr Dermatol 2008; 25: 444-8.

33. Lenane P, Powell FC. Oral pigmentation. J Eur Acad Dermatology Venereol 2000; 14: 448-65.

34. Aoki Y, Niihori T, Inoue SI, et al. Recent advances in RASopathies. J Hum Genet 2016; 61: 33-9.

35. Digilio MC, Conti E, Sarkozy A, et al. Grouping of multiplelentigines/LEOPARD and Noonan syndromes on the PTPN11 gene. Am J Hum Genet 2002; 71: 389-94.

36. Yanase S, Nomura J, Yamamoto W, et al. A case of Costello syndrome with delayed eruption of primary teeth. Asian J Oral Maxillofac Surg 2013; 25: 267-70.

37. Takahashi M, Ohashi H. Craniofacial and dental malformations in Costello syndrome: a detailed evaluation using multi-detector row computed tomography. Congenit Anom (Kyoto) 2013; 53: 67-72.

38. Gripp KW, Scott Cl, Nicholson L, et al. Five additional Costello syndrome patients with rhabdomyosarcoma: proposal for a tumor screening protocol. Am J Med Genet 2002; 108: 80-7.

39. Johnson JP, Golabi M, Norton ME, et al. Costello syndrome: phenotype, natural history, differential diagnosis, and possible cause. J Pediatr 1998; 133: 441-8.

40. Hennekam RCM. Costello syndrome: an overview. Am I Med Genet 2003; 117C: 42-8.

41. Costello JM. Costello syndrome: update on the original cases and commentary. Am J Med Genet 1996; 62: 199-201.

42. Allanson JE. Objective studies of the face of noonan, cardiofacio-cutaneous, and Costello syndromes: a comparison of three disorders of the Ras/MAPK signaling pathway. Am J Med Genet Part A 2016; 170: 2570-7.

43. Lorenz S, Petersen C, Kordaß U, et al. Two cases with severe lethal course of Costello syndrome associated with HRAS p.G12C and p.G12D. Eur J Med Genet 2012; 55: 615-9.

44. Gripp KW, Lin AE. Costello syndrome: a Ras/mitogen activated protein kinase pathway syndrome (rasopathy) resulting from HRAS germline mutations. Genet Med 2012; 14: 285-92.

45. Lin A, Harding C, Silberbach M. Insights hand it to the skin in Costello syndrome. J Pediatr 2004; 144: 135.

46. Dileone M, Zampino G, Profice P, et al. Dystonia in Costello syndrome. Park Relat Disord 2012; 18: 798-800.

47. Siegel DH, Mann JA, Krol AL, et al. Dermatological phenotype in Costello syndrome: consequences of Ras dysregulation in development. Br J Dermatol 2012; 166: 601-7.

48. White SM, Graham JM, Kerr B, et al. The adult phenotype in Costello syndrome. Am J Med Genet Part A 2005; 136A: 128-35.

49. Nguyen V, Buka RL, Roberts BJ, et al. Cutaneous manifestations of Costello syndrome. Int J Dermatol 2007; 46: 72-6.
50. Adigun CG, Pandya AG. Improvement of idiopathic acanthosis nigricans with a triple combination depigmenting cream. J Eur Acad Dermatol Venereol 2009; 23: 486-7.

51. Torrelo A, López-Avila A, Mediero IG, et al. Costello syndrome. J Am Acad Dermatol 1995; 32: 904-7.

52. Mori M, Yamagata T, Mori Y, et al. Elastic fiber degeneration in Costello syndrome. Am J Med Genet 1996; 61: 304-9.

53. Umans S, Decock P, Fryns JP. Costello syndrome: the natural history of a true postnatal growth retardation syndrome. Genet Couns 1995; 6: 121-5.

54. Della Marca G, Vasta I, Scarano E, et al. Obstructive sleep apnea in Costello syndrome. Am J Med Genet A 2006; 140: 257-62.

55. Di Rocco M, Gatti R, Gandullia P, et al. Report on two patients with Costello syndrome and sialuria. Am J Med Genet 1993; 47: 1135-40. 